\title{
Maternal and perinatal outcome following assisted reproductive technology in a tertiary care centre: a retrospective study
}

\author{
Durga Valvi, Girija Swaminathan*
}

Department of Obstetrics and Gynecology, Seth G.S. Medical college and King Edward Memorial Hospital, Mumbai, India

Received: 22 March 2019

Accepted: 02 April 2019

*Correspondence:

Dr. Girija Swaminathan,

E-mail: girija.swaminathan@yahoo.com

Copyright: (C) the author(s), publisher and licensee Medip Academy. This is an open-access article distributed under the terms of the Creative Commons Attribution Non-Commercial License, which permits unrestricted non-commercial use, distribution, and reproduction in any medium, provided the original work is properly cited.

\begin{abstract}
Background: Infertility is a major issue and a source of social and psychological suffering for many couples. Introduction of assisted reproductive technology (ART) leads to great relief for couples nowadays.

Methods: Present study was a retrospective study conducted at K.E.M hospital, a major tertiary care hospital after approval of the institutional ethics committee. A retrospective analysis of maternal and perinatal outcome of 30 cases of ART conception from the year 2014 to 2018 was done.

Results: The mean age of women enrolled into present study was 37.6 years and most common age group was 30-50 years. The main cause of infertility was unexplained (40\%), other causes were female factor $(33.33 \%)$, male factor $(16.67 \%)$ and combined (10\%). $63.33 \%$ pregnancies were singleton and $36.67 \%$ twin gestations. The most common complication seen was preterm labour $(43.33 \%)$. The other complications were preeclampsia/eclampsia (33.33\%), gestational hypertension, renal failure, gestational diabetes, cardiomyopathy, hepatic failure, HELLP syndrome and DIC. $60 \%$ patients had caesarean section and $40 \%$ had vaginal delivery.90.24\% neonates had 5-minute Apgar score of more than or equal to 7 and $9.76 \%$ had score less than 7 . There were 4 stillbirths accounting for $9.76 \%$ and out of live births, $75.68 \%$ babies required NICU admission. There were 5 neonatal deaths $(12.2 \%)$ and perinatal death rate was $21.95 \%$.

Conclusions: ART is associated with a variety of maternal and perinatal complications. Couples should therefore be counseled about these risks while offering them ART as a mode of conception.
\end{abstract}

Keywords: ART, Adverse outcomes of ART, Infertility, Perinatal complications, Renal failure

\section{INTRODUCTION}

Infertility is a medical condition in which there is failure to conceive after one of unprotected sexual intercourse. Nearly 1 in 6 couples face the problem of infertilty. ${ }^{1}$ It is a major issue and a source of social and psychological suffering for many couples nowadays. Introduction of assisted reproductive technology (ART) leads to great relief for couples as approximately $10 \%$ couples nowadays need the help of assisted reproductive technology for conception.
ART involves manipulation of gametes or the embryo outside the body and it includes: in-vitro maturation (IVM), in-vitro fertilization (IVF), intracytoplasmic sperm injection (ICSI), gamete intrafallopian transfer (GIFT) and zygote intrafallopian transfer ( ZIFT).

In-vitro maturation involves collection of immature oocyte and process of maturing it in culture media. If a follicle has reached the antral stage, this procedure can be carried out. In vitro fertilization is the simplest ART procedure; IVF has been around for over 20 years and is 
perhaps the most commonly recognized ART procedure. IVF involves a sequence of highly coordinated steps beginning with controlled ovarian hyperstimulation with exogenous gonadotrophins, followed by retrieval of oocytes from the ovaries under the guidance of transvaginal ultrasound, then fertilization in the laboratory followed by transcervical transfer of embryos into the uterus. IVF needs 50 to 100 thousand sperms. ICSI is an IVF procedure in which a single sperm cell is directly injected into the cytoplasm of an egg. This technique is used in order to prepare the gametes for the obtention of embryos that may be transferred to a maternal uterus. With this method, acrosome reaction is skipped. The steps that are to be followed before and after insemination are the same. ICSI needs one only sperm cell per oocyte. In GIFT, eggs are removed from a female's ovaries, and then placed in one of the fallopian tubes, along with the male's sperm. This allows fertilization to take place inside the woman's uterus. ZIFT is an ART treatment which used when a blockage in the fallopian tubes prevents the normal binding of the sperm to the egg. Egg cells are removed from ovaries and fertilized it in vitro.

ART pregnancy is associated with increased incidence of maternal complications like multiple gestation, preterm delivery, gestational diabetes mellitus, pregnancy induced hypertension, preeclampsia, placenta previa, and also there are increased chances of operative intervention in ART pregnancies. ${ }^{2}$ Multiple pregnancy is the most notable factor associated with adverse pregnancy outcome in ART. ${ }^{3-6}$ Additionally, there are increased risks of chromosomal anomalies in fetus, still birth, low birth weight, preterm birth, adverse neurodevelopmental outcome and high infant mortality is observed in ART pregnancies. $^{3-5}$ India is now becoming a global centre for ART.

In India, cost of ART is nearly 1-1.5 lakhs per cycle. Economy in India has expanded, and hence many infertile couples can now afford this sophisticated ART treatment. Unfortunately, there is a strong association between assisted conception and complications related to pregnancy and birth. Couples with already depleted resources present to tertiary care centres for the management of these complications. The purpose of this study is to determine the maternal and fetal outcome following assisted reproductive technology in cases referred to our tertiary care hospital.

\section{METHODS}

Present study was a retrospective observational study conducted at King Edward Memorial Hospital, in India which is a major tertiary care referral hospital. Study commenced after approval of the institutional ethics committee. A retrospective analysis of 30 cases of ART conception admitted at our tertiary care center from the year 2014 to 2018 was done and data was recorded in the data record form.

\section{Inclusion criteria}

- Present study included all patients conceived through assisted reproductive technology that were referred to our tertiary care center for ANC registration and management of pregnancy, who were referred to our center in labour and those who presented to our hospital post-delivery for management of maternal complications or for NICU admission.

\section{Exclusion criteria}

- $\quad$ Present study excluded patients conceived following ovulation induction and intrauterine insemination.

All patients who fulfilled inclusion criteria were enrolled into the study. Patients were enrolled by scrutinizing records from inpatient admission register and confinement book and all data regarding these patients was obtained by analysing records from medical record department. As this was a retrospective study, waiver of consent was sought for all these cases. From the history and case records, information was collected regarding socio-demographic details and economic status. Relevant past medical and surgical history was recorded. Details regarding the patient's obstetric history, type of infertility, the treatment taken, complete details regarding the ART procedure and referral details were recorded. Details of general physical examination and routine investigations were recorded. Also details of mode of delivery, maternal and fetal outcome were recorded. Maternal outcome was studied in detail and any complications which had occurred were recorded. Perinatal outcome was recorded in terms of preterm births, Apgar scores at 1 and 5 minutes, need for neonatal intensive care unit (NICU) admission and reason for NICU admission and number of still births and neonatal deaths.

\section{Statistical analysis}

As it was an observational study, simple statistical calculations were performed using numbers and percentages. The results are represented using tables or graphs for ease of understanding.

\section{RESULTS}

A total of 30 cases were included in present study based on the inclusion and exclusion criteria. Out of 30,21 cases were referred to our hospital for pregnancy induced complications for management of pregnancy after ART conception and 9 cases were registered at our hospital after ART conception for routine pregnancy management. The socio-demographic characteristics of the women enrolled in present study were recorded. The table 1 below shows the age distribution of the cases where it is observed that more than half of the women were in the age group of $30-50$ years $(60 \%)$, one third 
were less than 30 years old $(33.33 \%)$ and only 2 women were more than 50 years old $(6.67 \%)$.

Table 1: Age distribution of the women conceived through ART.

\begin{tabular}{|lll|}
\hline Age in years & Number of cases $(\mathbf{n}=\mathbf{3 0})$ & $(\%)$ \\
\hline$<30$ & 10 & 33.33 \\
\hline $31-40$ & 9 & 30 \\
\hline $41-50$ & 9 & 30 \\
\hline$>50$ & 2 & 6.67 \\
\hline
\end{tabular}

The women who were included in present study had varied years of married life after which they had opted for ART conception. The highest percentage of women had 5-10 years of married life $(43.33 \%)$, one third had less than 5 years of married life $(33.33 \%)$. Out of the remaining, $16 \%$ were married since $11-15$ years, $3.33 \%$ had a married life of 16-20 years and more than 20 years each. The above details have been demonstrated in table 2 below.

Table 2: Years of married life of ART conceived women.

\begin{tabular}{|lll|}
\hline $\begin{array}{l}\text { Years of married } \\
\text { life }\end{array}$ & $\begin{array}{l}\text { Number of cases } \\
(\mathbf{n = 3 0})\end{array}$ & $(\%)$ \\
\hline$<5$ & 10 & 33.33 \\
\hline $5-10$ & 13 & 43.33 \\
\hline $11-15$ & 5 & 16.67 \\
\hline $16-20$ & 1 & 3.33 \\
\hline$>20$ & 1 & 3.33 \\
\hline
\end{tabular}

The main causes of infertility were studied which included male factor, female factor, unexplained and both male and female factor combined. It was observed that male factor infertility was seen in $16.67 \%$, female factor in $33.33 \%$, both male and female factor infertility were seen in $10 \%$ and cause was unexplained in $40 \%$ of the cases.

Table 3: The various causes of infertility.

\begin{tabular}{|lll|}
\hline Cause of infertility & $\begin{array}{l}\text { Number of } \\
\text { cases }(\mathbf{n}=30)\end{array}$ & percentage \\
\hline Male factor & 5 & 16.67 \\
\hline Female factor & 10 & 33.33 \\
\hline $\begin{array}{l}\text { Both male and } \\
\text { female factor }\end{array}$ & 3 & 10 \\
\hline Unexplained & 12 & 40 \\
\hline
\end{tabular}

Thus, the most common cause of infertility in present study was unexplained infertility followed closely by female factor infertility. Also $50 \%$ of the cases studied had primary infertility and the remaining $50 \%$ had secondary infertility. (Table 3) below outlines the main causes of infertility in present study.

\section{Type of gestation}

In present study, it was observed that $63.33 \%$ had singleton pregnancy and $36.67 \%$ had twin pregnancy. There were no higher order pregnancies in present study. (Table 4) below outlines the types of gestation.

Table 4: Types of gestation.

\begin{tabular}{|lll|}
\hline Gestation type & $\begin{array}{l}\text { Number of cases } \\
(\mathbf{n = 3 0})\end{array}$ & Percentage \\
\hline Singleton pregnancy & 19 & 63.33 \\
\hline Multiple pregnancy & 11 & 36.67 \\
\hline
\end{tabular}

\section{Pregnancy and perinatal complications}

Significant number of pregnancy complications were seen in pregnancies achieved through ART. Perinatal complications were also more commonly seen in ART conception compared to natural conception. Out of 30 patients enrolled in present study, $23(77 \%)$ patients had pregnancy and perinatal complications and only 7 (23\%) patients had no complications during pregnancy as well as perinatally. Multiple complications were seen in some patients and hence, the total number of complications was more than the total number of patients.

Total 9 out of 23 patients who had complications needed intensive care unit admission for management of pregnancy induced complications (30\%out of total 30 patients). There were no maternal deaths in present study. Preterm delivery rate was higher in present study due to requirement of induction of labour in these patients for maternal complications.

Table 5: Pregnancy and perinatal complications seen in ART pregnancies.

\begin{tabular}{|lll|}
\hline Complication observed & $\begin{array}{l}\text { Number of } \\
\text { patients with } \\
\text { the complication }\end{array}$ & $(\%)$ \\
\hline Gestational hypertension & 7 & 23.33 \\
\hline Preeclampsia /eclampsia & 10 & 33.33 \\
\hline Renal failure & 5 & 16.67 \\
\hline Hepatic failure & 2 & 6.67 \\
\hline $\begin{array}{l}\text { Disseminated } \\
\text { intravascular coagulation }\end{array}$ & 2 & 6.67 \\
\hline Gestational diabetes & 4 & 13.33 \\
\hline Intracranial bleed & 1 & 3.33 \\
\hline Cardiomyopathy & 4 & 13.33 \\
\hline Pancreatitis & 1 & 3.33 \\
\hline HELLP syndrome & 2 & 6.67 \\
\hline Preterm labour & 13 & 43.33 \\
\hline
\end{tabular}

Out of 30, total 13 patients had preterm delivery out of which 9 were twin gestation and 4 were singleton pregnancies. The pregnancy and perinatal complications that were seen in present study are listed below in (Table 5). 


\section{Mode of delivery}

Operative deliveries were more common in pregnancies following assisted reproductive technology. The most common mode of delivery was cesarean section which reflects the high incidence of maternal and fetal complications in present study population. ${ }^{18}$ patients needed cesarean section, 12 patients delivered vaginally out of which 1 patient required outlet

forceps application due to fetal distress. (Figure 1), below shows the various modes of delivery of the patients enrolled in present study.

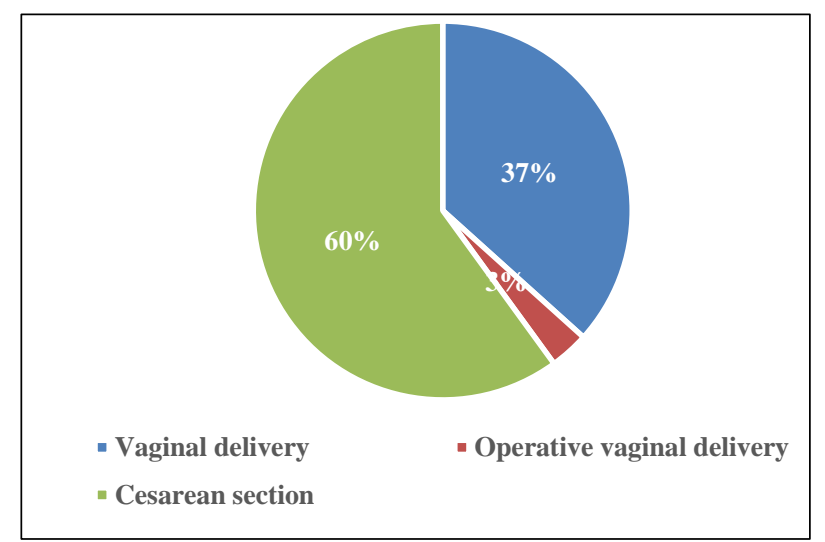

Figure 1: Modes of delivery.

(Figure 2), below demonstrates the various indications of cesarean section in present study patients. Most common indication was fetal distress seen in 9 patients $(50 \%)$ followed by malpresentation in 5 patients $(28 \%)$. The other indications seen were non progress of labour seen in 3 patients $(17 \%)$ and placenta previa was the indication in 1 patient $(5 \%)$.

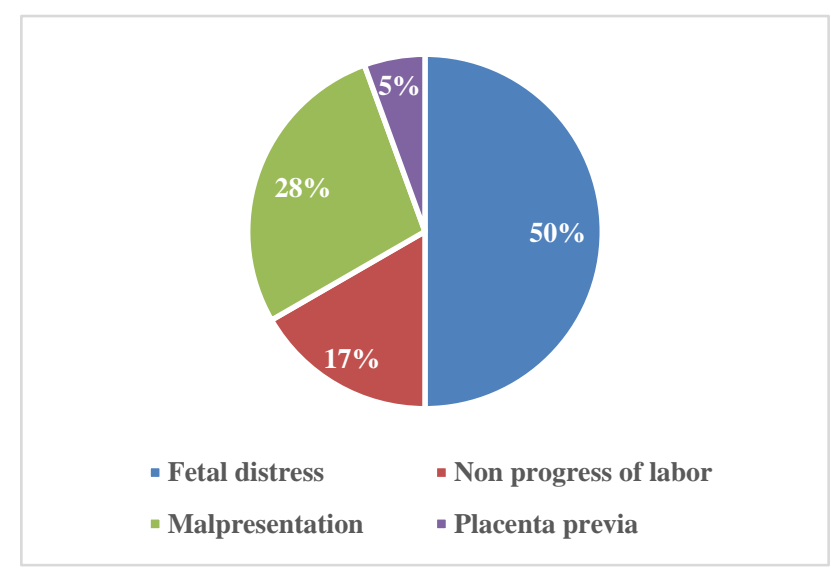

Figure 2: Various indications of caesarean section.

\section{Perinatal outcome}

Out of total 30 cases, 19 women had singleton gestations and 11 women had twin gestations. So, a total of 41 babies were studied for perinatal outcome following ART conception.

The perinatal outcome was analysed in present study in terms of Apgar scores at 5 minutes, the number of neonates who required admission to neonatal intensive care unit and the number of stillbirths and neonatal deaths. 90.24\% neonates showed Apgar score equal to or greater than 7 and less than 7 Apgar score was seen in $9.76 \%$ neonates as shown in (Table 6).

Table 6: Apgar score at 5 minutes after birth.

\begin{tabular}{|lll|}
\hline $\begin{array}{l}\text { 5-minute A pgar } \\
\text { score }\end{array}$ & $\begin{array}{l}\text { Number of } \\
\text { neonates }(\mathrm{n}=41)\end{array}$ & $(\%)$ \\
\hline$<7$ & 4 & 9.76 \\
\hline$\geq 7$ & 37 & 90.24 \\
\hline
\end{tabular}

There were total 4 stillbirths accounting for $9.76 \%$. All 4 still born babies were extremely premature with gestational age around 24-25 weeks and induction of labor was done in them for maternal interest due to pregnancy induced complications.

28 babies out of 37 live births (75.68\%) needed NICU care, mainly due to preterm birth and low birth weight. Out of 28 NICU admissions, 22 babies needed NICU care due to prematurity, 3 babies had intrauterine growth retardation, 3 babies had intrauterine growth retardation and prematurity both. NICU outcome was favourable in 23 babies out of 28 accounting for $82.14 \%$ and these babies were discharged alive and 5 babies died in the neonatal period accounting for an overall neonatal death rate of $12.2 \%$. 3 neonatal deaths were due to extreme prematurity with birth weight less than 700 grams.

Table 7: NICU outcome of babies admitted to NICU.

\begin{tabular}{|lll|}
\hline NICU outcome & $\begin{array}{l}\text { Number of babies } \\
(\mathbf{n = 2 8})\end{array}$ & $(\%)$ \\
\hline Neonatal death & 5 & 17.86 \\
\hline Discharged alive & 23 & 82.14 \\
\hline
\end{tabular}

One neonatal death was due to extreme prematurity with pulmonary haemorrhage in which birth weight was 890 grams. Another baby which died in the neonatal period had multiple congenital anomalies with multi cystic dysplastic kidney, an hydramnios and ambiguous genitalia. NICU outcome is outlined below in Table 7.

The total number of perinatal deaths (which included stillbirths and neonatal deaths) was 9 out of 41 births. Thus, the overall perinatal mortality was $21.95 \%$.

\section{DISCUSSION}

ART is a life science which is now showing an upward trend due to rising incidence of infertility in present day couples. Due to accelerating pace of life, increasing work 
pressure, worsening environmental pollution and delayed age of marriage, the incidence of infertility is increasing year by year.

\section{Sociodemographic characteristics}

The mean age of women enrolled into present study was 37.6. More than half of the women were in the age group of $30-50$ years $(60 \%)$, one third were less than 30 years old $(33.33 \%)$ and only 2 women were more than 50 years old $(6.67 \%)$.Our findings were similar to a study conducted by Jie $\mathrm{Z}$ et al, in the Republic of China where the mean age of ART conceived women was $32.53 .^{7}$

\section{Types of gestation}

In present study, it was observed that $63.3 \%$ had singleton pregnancy and $36.3 \%$ had twin pregnancy. Similar results were found in a study conducted by Jie Z et al, in Zhejiang university in China where out of total ART conceptions studied, $62.8 \%$ were singleton gestations and $37.2 \%$ were twin gestations. ${ }^{8}$ The explanation give for this was the common practice of single embryo transfer that is followed nowadays during in vitro fertilization. This is mainly done to avoid the complications of multiple pregnancy.

\section{Pregnancy and perinatal complications}

Various pregnancy and perinatal complications were seen in ART pregnancies. The most common complication seen in present study was preterm labour which occurred in $43.33 \%$ of our cases. The second most common complication seen was preeclampsia/eclampsia which was seen in $33.33 \%$ patients followed by gestational hypertension which was seen in $23.33 \%$ cases. The other complications which were observed in present study were renal failure $(16.67 \%)$, gestational diabetes $(13.33 \%)$, cardiomyopathy $(13.33 \%)$, hepatic failure $(6.67 \%)$, HELLP syndrome (6.67\%), DIC (6.67\%), and other rare complications like intracranial bleed (3.33\%) and pancreatitis $(3.33 \%)$. Our findings were supported by a study conducted by Gao et al, where the incidence of preterm delivery, low birth weight and small for gestational age babies was high in ART conception. ${ }^{9}$ Similarly, Pinborg et al found a higher preterm delivery rate in IVF/ICSI pregnancies. ${ }^{10}$ Zhang et al, reported significantly higher rates of pre-eclampsia and gestational diabetes mellitus in the ART group which was also found in present study. ${ }^{7}$ Zhu et al also reported various complications observed in ART conceptions which included preeclampsia/eclampsia, gestational diabetes mellitus, intrahepatic cholestasis of pregnancy, placenta previa, placental abruption, polyhydramnios and postpartum hemorrhage. ${ }^{8}$

\section{Modes of delivery}

An Australian study by Wang AY et al, showed cesarean section rates of $82 \%$ in ART patients. ${ }^{3}$ In present study, comparable but slightly lower rates were seen. The mode of delivery was caesarean section in $60 \%$ of our patients and $40 \%$ had a vaginal delivery. The reason for cesarean section rates generally being higher than vaginal delivery in ART conception could be due to the pregnancy being a precious one arising after long periods of infertility and hence, trial for normal vaginal delivery is given in fewer patients and most patients opt for elective cesarean sections.

\section{Perinatal outcome}

It is well documented that there is a higher proportion of multiple pregnancies in ART pregnancies and multiple gestation is associated with increased risk of adverse perinatal outcomes. Therefore, the strategy of elective single embryo transfer (e SET) and additional cycles with transfer of frozen/thawed embryos which has to a large extent decreased the incidence of multiple pregnancies is now used in many countries. ${ }^{11}$ However, current evidences suggest that risks are increased even in singleton ART pregnancies. The multifactorial reasons for the increase in adverse outcomes with ART are not known. One hypothesis is that underlying infertility related diagnoses of the women who undergo ART contribute directly to the adverse outcomes. Another possibility is that the ART itself (including embryo culture, embryo cryo-preservation, etc.) could have negative impacts on the ART offspring. Moreover, the influence of ovarian hyper stimulation on the perinatal outcome should not be neglected. ${ }^{9}$ The perinatal outcome was analyzed in present study in terms of Apgar scores at 5 minutes, the number of neonates who required admission to neonatal intensive care unit and the number of stillbirths and neonatal deaths.

The Apgar score at 5 minutes after birth, and particularly a change in this score between 1 minute and 5 minutes, is a useful index of the response to resuscitation. If the Apgar score is found to be less than 7 at 5 minutes, the neonatal resuscitation program guidelines state that the assessment of Apgar score should be repeated every 5 minutes for up to 20 minutes. ${ }^{12}$ If the Apgar score at 5 minutes is found to be 7 or greater than 7 , it is unlikely that peripartum hypoxia or ischemia has caused neonatal encephalopathy, hence authors have taken margin of Apgar score as 7 or more and less than $7 .{ }^{13} 90.24 \%$ neonates showed Apgar score equal to or greater than 7 and less than 7 Apgar score was seen in $9.76 \%$ neonates. Daniel Y et al, also found significantly higher rate of low $5^{\text {th }}$ min Apgar scores $(<7)$ in ART group compared to spontaneous group. ${ }^{14}$ Pourali L et al, found no significant increase in rates of low 5-minute Apgar scores between ART and spontaneous conception group. This could be due to their small sample size and lower number of preterm deliveries as compared to present study. ${ }^{15}$ Also, around three quarters of the babies (75.68\%) needed NICU care in present study, mainly due to preterm birth and low birth weight. Similarly, high rates of NICU requirement were seen in studies done by Caserta et al 
and Daniel Yet al, respectively. ${ }^{14,16}$ A study conducted by Wang et al in Australia also reported $66 \%$ rate of neonatal admission to intensive care units in ART pregnancies. ${ }^{3}$ There were total 4 stillbirths and 5 neonatal deaths in present study giving rise to an overall perinatal death rate of $21.95 \%$. A research done by Chughtai AA et al, also concluded with a perinatal death rate $16.5 \%$ which was comparable to present study. ${ }^{17}$

\section{CONCLUSION}

Assisted reproductive technology is thus associated with a variety of maternal and perinatal complications. One of the main reasons for this could be the older age of women who opt for it and also the background of infertility present in these couples and the high-risk factors associated with it. Couples should therefore be counseled about these risks while offering them ART as a mode of conception. ART although is a very promising and useful mode of conception, it should be used as a last option in couples where all other methods of treatment of infertility have been tried and been unsuccessful.

Funding: No funding sources

Conflict of interest: None declared

Ethical approval: The study was approved by the Institutional Ethics Committee

\section{REFERENCES}

1. Farquhar C, Marjoribanks J. Assisted reproductive technology: an overview of Cochrane Reviews. Coch Databas Systemat Revi. 2018(8).

2. Yang X, Li Y, Li C, Zhang W. Current overview of pregnancy complications and live-birth outcome of assisted reproductive technology in mainland China. Fertil Steril. 2014;101(2):385-91.

3. Wang AY, Safi N, Ali F, Lui K, Li Z, Umstad MP, et al. Neonatal outcomes among twins following assisted reproductive technology: an Australian population-based retrospective cohort study. BMC Pregnancy Childbirth. 2018;18(1):320.

4. Göçmen A, Güven Ş, Bağci S, Çekmez Y, Şanlıkan F. Comparison of maternal and fetal outcomes of IVF and spontaneously conceived twin pregnancies: three year experience of a tertiary hospital. Int J clinic Exp Med. 2015;8(4):6272.

5. Saccone G, Zullo F, Roman A, Ward A, Maruotti G, Martinelli P, et al. Risk of spontaneous preterm birth in IVF-conceived twin pregnancies. J Mater Fetal Neonatal Med. 2019;32(3):369-76.

6. Luke B, Stern JE, Kotelchuck M, Declercq ER, Anderka M, Diop H. Birth outcomes by infertility treatment: analyses of the population-based cohort Massachusetts outcomes study of assisted reproductive technologies (MOSART). J Reprod Med. 2016;61(3-4):114.

7. Jie Z, Yiling D, Ling Y. Association of assisted reproductive technology with adverse pregnancy outcomes. Iranian J Reprod Med. 2015;13(3):169.

8. Zhu L, Zhang Y, Liu Y, Zhang R, Wu Y, Huang Y, et al. Maternal and live-birth outcomes of pregnancies following assisted reproductive technology: a retrospective cohort study. Scient Reports. 2016;6:35141.

9. Gao L, Yang S. Perinatal outcomes of children born after assisted reproduction technology: A review. Austin J Reprod Med Infertil. 2015;2(5):1025.

10. Pinborg A, Wennerholm UB, Romundstad LB, Loft A, Aittomaki K, Söderström-Anttila V, et al. Why do singletons conceived after assisted reproduction technology have adverse perinatal outcome? Systematic review and meta-analysis. Human Reprod Update. 2012;19(2):87-104.

11. McLernon DJ, Harrild K, Bergh C, Davies MJ, De Neubourg D, Dumoulin JC, et al. Clinical effectiveness of elective single versus double embryo transfer: meta-analysis of individual patient data from randomised trials. BMJ. 2010;341:c6945.

12. American academy of pediatrics and American heart association. Textbook of neonatal resuscitation, 6th ed. Elk Grove Village, In: American academy of pediatrics and American heart association. 2011.

13. The Apgar score. Committee Opinion No. 644. American college of obstetricians and gynecologists. Obstet Gynecol. 2015;126:e52-5.

14. Daniel Y, Ochshorn Y, Fait G, Geva E, Bar-Am A, Lessing JB. Analysis of 104 twin pregnancies conceived with assisted reproductive technologies and 193 spontaneously conceived twin pregnancies. Fertil Steril. 2000;74(4):683-9.

15. Pourali L, Ayati S, Jelodar S, Zarifian A, Andalibi MS. Obstetrics and perinatal outcomes of dichorionic twin pregnancy following ART compared with spontaneous pregnancy. Int $\mathrm{J}$ Reprod Bio Med. 2016;14(5):317.

16. Caserta D, Bordi G, Stegagno M, Filippini F, Podagrosi M, Roselli D, et al. Maternal and perinatal outcomes in spontaneous versus assisted conception twin pregnancies. European J Obstet Gynecol Reprod e Biol. 2014;174:64-9.

17. Chughtai AA, Wang AY, Hilder L, Li Z, Lui K, Farquhar C, et al. Gestational age-specific perinatal mortality rates for assisted reproductive technology (ART) and other births. Human Reprod. 2017;33(2):320-7.

Cite this article as: Valvi D, Swaminathan $\mathrm{G}$ Maternal and perinatal outcome following assisted reproductive technology in a tertiary care centre: a retrospective study. Int J Reprod Contracept Obstet Gynecol 2019;8:1745-50. 